\title{
Rousseau e o espetáculo do paradoxo ${ }^{1}$
}

\author{
Mauro Sérgio Santos Da Silva* \\ Marcio Danelon ${ }^{* *}$
}

Resumo: O presente estudo discute a relação entre política e educação na obra de Jean-Jacques Rousseau a partir de autores que constituem a recepção crítica da obra do filósofo. Destarte, apresenta elementos da vida e da obra do autor genebrino. Expõe eixos fundamentais da ideia de contratualismo ou jusnaturalismo. Discorre, precipuamente, acerca das teses de Rousseau atinentes à confluência entre Do Contrato Social (reflexão política) e o Emílio ou da Educação (reflexão educacional). Exibe a ideia de paradoxo da liberdade presente na teoria política de Rousseau. Aponta para os desdobramentos deste paradoxo na reflexão educacional do autor, mormente nos dois primeiros livros do Emílio, pelo princípio de educação negativa.

Palavras-chave: Rousseau, Educação, Política, Liberdade, Paradoxo.

\section{Rousseau and the paradox of the spectacle}

\begin{abstract}
The present study discusses the relationship between politics and education in the Jean-Jacques Rousseau'work from authors who constitute the critical reception of this philosopher's work. By the way, show elements of the life and work of the Genevan author. It exposes fundamental axes of the idea of contractualism or jusnaturalism. It discusses Rousseau's theses concerning the confluence between The Social Contract (political reflection) and Emílio or Education (educational reflection). It shows the idea of the paradox of freedom present in Rousseau's political theory. It points to the unfolding of this paradox in the educational reflection of this author, especially in the first two books of the Emílio, by the negative education'principle.
\end{abstract}

Keywords: Education. Freedom. Paradox. Politics. Rousseau.

\section{Rousseau e seu tempo: a posição do filósofo na escola contratualista}

Jean-Jacques Rousseau (1712-1778) nasce em Genebra (Suíça). Sua mãe falece após seu nascimento. Ainda na infância, afasta-se do convívio do pai. Oriundo de família modesta, até a adolescência, vive grandes dificuldades e percalços. Viaja por alguns países da Europa até se estabelecer em Paris, por volta de 1742. Homem de

\footnotetext{
${ }^{1}$ Este estudo toma como ponto de partida as reflexões de Cassirer (1954) Chapan (1956), Cotta (1964) e Coletti (1972) que, no Brasil, encontram ressonância em Salinas Fortes (1997) Marques (2010) e Dos Santos (2017) acerca da ideia de paradoxo da liberdade em Rousseau. A propósito, o título faz referência direta ao trabalho de Salinas Fortes, intitulado "Paradoxos do Espetáculo" (1997).

*Doutorando em Educação pela Universidade Federal de Uberlândia (UFU). E-mail: mauro.filos@hotmail.com.

** Doutor em Filosofia da Educação pela Universidade Estadual de Campinas (UNICAMP) e professor da Universidade Federal de Uberlândia (UFU). E-mail: danelon@ faced.ufu.br.
} 
personalidade inquieta, Rousseau testemunha um contexto histórico caracterizado pelo embate entre o antigo e o novo regime, as instituições absolutistas e a emergência da burguesia. Suas ideias fazem parte do aporte teórico que fundamenta o ideário da Revolução Francesa. Convive com Diderot, D’ Alembert e, na Inglaterra, com o filósofo Hume (WEFFORT, 2006). Entre suas obras, destacam-se para este estudo: Discurso sobre a origem da desigualdade (1754) e, sobretudo, Do Contrato Social (1762) e $O$ Emílio ou da educação (1762).

Ao lado de Hobbes e Locke, Rousseau pertence a uma escola de pensadores modernos denominados contratualistas ou jusnaturalistas que argumentam em favor da tese de que a sociedade e sua ordenação política, o Estado, são empreendimentos (artifícios) humanos e não fenômenos naturais como postulara Aristóteles (1999), na Antiguidade.

Conforme Bobbio, o contratualismo em sentido amplo, diz respeito a todas as teorias políticas que discutem a origem da sociedade e o fundamento do poder político, do Governo, da soberania e do Estado mediante um Pacto Social. Em sentido estrito, designa a escola filosófica que surgiu na Europa por volta dos séculos XVII e XVIII. (BOBBIO, 1997, p. 272-275).

Segundo a noção de pacto ou contrato social, a sociedade (vida social) é instituída pelos seres humanos, por meio de um pacto coletivo - um contrato - com base no qual os indivíduos convivem. O contrato estabelece regras, leis e um poder que organiza a vida coletiva dos homens atuando, igualmente, como árbitro em suas disputas. Essa filosofia é conhecida como contratualismo ou jusnaturalismo (ABBAGNANO, 2007).

Nesse período, surgem questões cruciais ao pensamento político moderno, quais sejam: O que é o homem em seu estado natural, antes do convívio com outros homens? Por que o ser humano passa a viver em sociedade? Por que, afinal de contas, as pessoas aceitam submeter-se ao poder de outros? Não é mais interessante ser livre? Enfim, os homens vivem por conta própria ou necessitam de uma sociedade civil? (ABBAGNANO, 2007; SOËTARD, 2010).

Uma das teses dos chamados contratualistas é a do pensador Jean-Jacques Rousseau. Em Discurso sobre a Origem e os Fundamentos da Desigualdade entre os Homens (1999), Rousseau exalta e glorifica os valores da vida natural, vociferando contra a corrupção, a avareza e os vícios da famigerada sociedade "civilizada". Exalta a 
liberdade de que o "selvagem" goza em seu estado natural, em contraposição à artificialidade da vida em sociedade.

Na obra Do Contrato Social (1978), por seu turno, o filósofo investiga a origem do poder político e persegue uma justificativa para o fato de os seres humanos, originalmente livres, submeterem sua liberdade ao Estado e, além disso, a condição necessária para que o poder político seja legítimo.

Para Rousseau (1978), o fundamento do poder político é o pacto ou contrato social. Neste, cada cidadão, integraria sua vontade individual à vontade geral. E o Estado estaria dotado de legitimidade na medida em que realizasse a vontade geral. Com efeito, o povo é a fonte da legitimidade do poder do Estado. O cidadão deve respeito às leis, pois que estas representam a vontade geral. O respeito às leis é também um respeito por si mesmo, por sua própria vontade como cidadão, cujo interesse deve ser o bem comum.

As teses de Rousseau, em geral, são apresentadas em contraposição aos postulados de Locke e, mormente de Hobbes, o que não pode prescindir acuidade e de ponderações (CASSIRER,1954; DOS SANTOS, 2017).

Segundo Marques (2010, p.02), comumente, deparamo-nos com leituras da obra de Rousseau que o colocam em direção diametralmente oposta ao pensamento do filósofo inglês Thomas Hobbes (1588-1679). Na cultura midiática e universitária e em análises descompromissadas encontramos os pensamentos de Hobbes e Rousseau como respostas inconciliáveis e radicalmente distintas para as mesmas questões ${ }^{2}$.

O primeiro descreveria o homem como naturalmente mau e violento. Homo homini lúpus (O homem é o lobo do homem). O estado de natureza é delineado, neste caso, como um estado de guerra de todos contra cada um. O contrato social ocorre na medida em que cada indivíduo abre mão de sua liberdade individual em favor de um poder soberano exercido por um indivíduo ou assembleia. Para governar seres humanos

\footnotetext{
${ }^{2}$ Essa tese é corroborada pela pesquisa realizada pelo professor Gatti Jr (2014). ao analisar 12 autores traduzidos no Brasil que, entre 1939-2010 trataram ou discorreram acerca da obra de Rousseau, o pesquisador demonstra: a existência de análises favoráveis e desfavoráveis ao pensamento de Rousseau; o modesto êxito que poucos tiveram ao relacionar as ideias políticas, educacionais e pedagógicas de Rousseau; o predomínio da análise da obra de Rousseau no desenvolvimento da psicologia do desenvolvimento humano; a presença de análises sobremodo críticas à dimensão liberal da obra de Rousseau.
} 
propensos à violência e à maldade, o Governo deve paradigmaticamente se inspirar no Leviatã, figura sobrenatural descritao no livro de Jó: forte e absoluto (HOBBES, 1983).

Para Hobbes (1983), por isso o Estado existe: para proteger seus súditos de si mesmos. O Estado tem, porquanto, que ser soberano, forte, e administrar a espada sempre que alguém atente contra o outro. A função fundamental do Estado é a proteção da vida dos súditos. Não cabe questionamento algum ao Estado, porque questionar os meios empregados pelo soberano significaria incorre no risco de retornar ao estado de natureza em que a guerra é a regra. A política é um artifício surgido para que o homem garanta a própria vida, submetendo-se ao Estado.

Em termos gerais, Rousseau, por seu turno, descreve o estado de natureza como o âmbito da liberdade e de relativa tranquilidade. Em contrapartida à ideia do homo homini lúpus, figura em Rousseau a ideia do bonsauvage (bom selvagem).

Segundo Rousseau, nascemos livres porque, no estado de natureza, o homem é livre. Mas, de algum modo, aceitamos limitar essa liberdade natural ao aceitarmos a associação política (ROUSSEAU, 1978).

A existência do Estado gera obrigações, submissões ou, em outras palavras, impedimentos para o exercício pleno da liberdade. Há razões, entretanto, que nos levam a viver em sociedade, já que essa associação nos traz benefícios. É, portanto, por meio de um ato livre que instituímos a associação; como demonstra o Livro I da obra Do Contrato Social (1978).

Para Rousseau, o contrato que origina o Estado deve ser estabelecido por meio de uma decisão unânime dos membros contratantes, de modo que cada um, livremente, abandone sua liberdade natural para viver um novo tipo de liberdade: a liberdade civil. O poder político só é legítimo, para Rousseau, se houver essa unanimidade originária (ROUSSEAU, 1978, livro I).

Com efeito, conforme Marques (2010), uma leitura menos superficial das obras de Hobbes e Rousseau revela que ambos talvez compartilhem de diversos princípios essenciais em seus sistemas e que seus papeis dramáticos, por vezes, até se invertem; sendo comum, inclusive, "encontrar comentadores que colocam Hobbes entre os precursores do liberalismo político, ao passo que Rousseau é muitas vezes acusado de ser um inimigo da liberdade individual, e sumariamente incluído entre os defensores do 'totalitarismo"” (MARQUES, 2010, p. 03). 
Reflexões desta natureza e neste sentido, emanam entre outros, de trabalhos consagrados como os de Cassirer (1954) Chapan (1956), Cotta (1964) e Coletti (1972). Em direção análoga, afirma Fonseca Jr (2003, X): "para alguns, seus escritos constituiriam o fundamento da democracia moderna, já que orientam o debate sobre o contrato social na direção da soberania popular;" para outros, Rousseau é o inspirador do autoritarismo".

E é sob esta perspectiva que o encontro com a obra de Rousseau, conduz-nos à constatação do que o próprio pensador denominou "paradoxos". Referimo-nos, destarte, ao paradoxo da questão da liberdade politica no pensamento rousseaniano e seu eco para a questão educacional.

\section{O paradoxo da liberdade no contrato social de Rousseau}

Rousseau em seu Emílio, ou da Educação, afirmara

[...] Ousarei expor aqui a mais importante, a mais útil regra de toda a educação? Não se trata de ganhar tempo, mas de perdê-lo. Leitores vulgares, perdoai meus paradoxos, é preciso cometê-los quando refletimos, e, digam o que disserem, prefiro ser homem de paradoxos a ser homem de preconceitos (ROUSSEAU, 1995, p.96; SOËTARD, 2010, p. 55).

Paradoxo, do grego "paradoxos" e, em latim, "paradoxon". Nos dois casos designa um "conceito que é ou parece contrário ao comum" (CUNHA, 1997, p. 579). Segundo Abagnano, trata-se do "que é contrário à opinião da maioria, ou seja, ao sistema de crenças comuns a que se fez referência" (ABBAGNANO, 2007, p. 742).

O paradoxo ao qual este estudo se refere encontra-se exposto ao final do livro I da obra Do Contrato Social, trecho no qual Rousseau sugere a coerção, por parte do corpo político àqueles que se recusarem a obedecer à Vontade Geral. Nas palavras de Rousseau:

[...]A fim de que não constitua, pois, um formulário inútil, o pacto social contém tacitamente esta obrigação, a única a poder dar forças às outras: quem se recusar a obedecer à vontade geral a isto será constrangido pelo corpo em conjunto, o que apenas significa que será forçado a ser livre. Assim é esta condição: oferecendo os cidadãos a prática, protege-os de toda dependência pessoal; condição que promove o artifício e o jogo da máquina política e que é a única a tornar legitima as obrigações civis, as quais, sem isso, seriam absurdas, tirânicas e sujeitas aos maiores abusos (ROUSSEAU, 1978, p.39). 
Tal recomendação do filósofo genebrino se justificaria pelo propósito de forçar o indivíduo a ser livre. E, neste caso, Rousseau não estaria "simplesmente declarando que a vida em sociedade exija certas restrições à liberdade individual, mas sim que é exatamente o poder coercitivo do corpo político que torna o homem livre" (MARQUES, 2010, p.01).

Encontramos justamente neste aspecto, no pensamento político de Rousseau, a ideia incomum no sentido de paradoxal de uma necessária coerção com vistas à promoção da liberdade, ideia, esta, que, no imaginário acadêmico, estaria muito mais próxima das consignações hobbesianas.

Diferentemente de Hobbes (1983) e Locke (1983; 1998), que admitem as restrições da liberdade individual em função dos objetivos e necessidades da vida social, Rousseau propõe que as coerções impostas pelo contrato social não sejam compreendidas como obstruções à liberdade, mas como meios pelos quais se garante a existência de uma forma de associação em que cada indivíduo obedeça apenas a si mesmo, permanecendo destarte, livre.

O paradoxo da liberdade política (próprio da filosofia política). A proposta de coerção como mecanismo de promoção da liberdade: Forçar a ser livre. E o paradoxo da conciliação das doutrinas políticas fortemente coletivistas com a apaixonada defesa de Rousseau da ideia de homem livre, solitário e independente.

Para Rousseau, os cerceamentos da liberdade individual não devem ser concebidos como tal, mas como condição sinequa non da própria liberdade (política). $\mathrm{Na}$ perspectiva do filósofo suíço, a vontade individual está integrada à vontade geral. Liberdade é diferente de independência. É também impensável estanque da justiça (ROUSSEAU, 2006). Assim afirma Rousseau:

[...]Não há, pois liberdade sem leis, nem onde alguém esteja acima das leis: pois até mesmo no estado de natureza o homem só é livre de acordo com a lei natural que comanda a todos. Um povo livre obedece, mas não serve. (ROUSSEAU, 1966, p. 372-373 apud MARQUES, 2010, p. 08).

Contudo, demonstra Marques (2010), que esse raciocínio não consegue ocultar a incompatibilidade entre interesses individuais e coletivos na medida em que sempre que os primeiros estiverem em conflito ou desacordo em relação a determinações legais, estas serão concebidas como empecilhos à liberdade. Em outras palavras, sempre que 
um indivíduo tiver que obedecer a uma lei com a qual não concorda, perceberá esta determinação como uma limitação, um cerceamento e/ou uma opressão por parte do Estado.

Desse modo, cabe pensar se a filosofia de Rousseau, evocada amiúde como um hino ou apelo à liberdade não estaria, em verdade, lançando mão desta categoria para justificar sua própria restrição pelo corpo político. À maneira dos regimes totalitários, Rousseau não estaria usando o conceito de liberdade para designar justamente o seu oposto? Ou Rousseau teria um conceito próprio de liberdade que não foi suficientemente compreendido pela recepção crítica de sua obra?

Conforme Marques (2010), o paradoxo da liberdade coloca os estudiosos da obra de Rousseau diante de um desafio tão grandioso quanto o pensamento do filósofo suíço que teria investigado mais profundamente que seus antecessores (e boa parte dos seus sucessores) as condições de possibilidade da liberdade política, bem como de sua compatibilidade com requisitos da vida em sociedade.

Consideramos, pois, que a leitura da obra de Rousseau admite "linhas variadas de interpretação". Ora, vista como uma "imposição de uma ditadura popular". Por vezes, traduzida como "receita paradoxal de democratizar pela força" (FONSECA JR, 2003, X).

Evidentemente, este trabalho não tem a pretensão de apontar postulados definitivos para questões tão complexas. Todavia, alvitra para o reverberar desse (ou desses) paradoxo na reflexão educacional do filósofo, como veremos adiante.

\section{Educação e política a partir de Rousseau}

Aportados à recepção crítica da obra de Rousseau, sustentamos que o projeto educacional de Rousseau guarda relação intrínseca com o empreendimento político. Por conseguinte, apontamos para a ideia de que o paradoxo da liberdade contido em Do Contrato Social encontra desdobramentos no Emílio.

Para a reflexão educacional, a leitura da obra de Rousseau é 
se estende de Descartes a Hegel) a construir um pensamento em que a educação vem ocupar um lugar central de reflexão (MORAIS, 1986, P.199).

O século XVIII desenvolve uma nova imagem relativa à pedagogia moderna que reverbera nos séculos que se seguem até nossos dias. Em termos gerais, pode assim ser descrita: "laica, racional, científica, orientada para valores sociais e civis, crítica em relação a tradições e instituições, crenças e praticas e educativa", e principalmente "empenhada em reformar a sociedade também na vertente educativa, sobretudo a partir da vertente educativa" (CAMBI, 1999, p.329).

Neste contexto, consolida-se a pedagogia iluminista: teoricamente "mais livre", socialmente mais ativa, mais articulada à prática e "orientada para fins sociais e civis" (CAMBI, 1999, p. 330).

Entre os pensadores que sintetizam essa concepção pedagógica, encontram-se: D’Alambert (1717-1783), Diderot (1713-1784), Voltaire (1694-1778), Condillac (17151780), Basedow (1723-1790), Lessing (1729-1781), entre outros. Com efeito, Rousseau é "a voz mais alta, mais complexa e mais original do século e realizará uma das maiores lições teóricas da pedagogia moderna". Autor que realizara a virada mais explícita da sua história moderna em termos educacionais, responsável por uma espécie de “revolução copernicana” em matéria de educação (CAMBI, 1999, p. 338).

Conforme Morais (1986), na esteira do pensamento socrático-platônico, Rousseau traduz o postulado do "conhece-te a ti mesmo" para os princípios gerais da filosofia, desdobrando-o em três grandes questões, discutidas, respectivamente em suas obras mais conhecidas, quais sejam: Discurso sobre as origens e os fundamentos das desigualdades entre os homens, Do Contrato Social e Emílio ou da Educação.

Em Discursos sobre as origens e os fundamentos das desigualdades entre os homens (1999) Rousseau discute a seguinte questão: “O que é o homem?” Em Do Contrato Social (1978), a questão central não é outra senão "Que sociedade para este homem?". Por fim, no Emílio (1995), o filósofo genebrino discorre sobre o “como educar o homem para uma vida melhor em sociedade?” (MORAIS, 1986, p. 200-201).

$\mathrm{Na}$ confluência dessas três questões, Rousseau define o homem como um ser originalmente bom, livre e isento de vícios; mas, concomitantemente, corrompido, dada 
a sua adesão ao escopo social. Dotado de perfectibilidade, ou seja, da capacidade de aperfeiçoar-se amiúde, mas corruptível. Corruptível, todavia, passível de ser educado.

Para Rousseau, com vistas à organização da sociedade por meio do chamado contrato social, afigura-se "necessária uma educação ética que habilite os homens a renunciarem em conjunto a suas vontades particulares em prol do bem comum e do interesse coletivo" (VEIGA, 2007, p. 43).

Na obra Do Contrato Social (1978), como anteriormente demonstrado, o filósofo concebe um pacto inaugural que marca a passagem do estado de natureza ao estabelecimento da vida em sociedade. Em linhas gerais, a associação dos homens (a vida em sociedade) deve defender a pessoas e os bens de seus associados como a força do coletivo. A sociedade constituída deve estar fundamentada na harmonia e integração entre o social e o coletivo possibilitando que cada um, unindo-se a todos, permaneça, entretanto, tão livre quanto antes (MORAIS, 1986).

\section{Conforme o filósofo,}

[...]Encontrar uma forma de associação que defenda e proteja com toda a força comum a pessoa e os bens de cada associado, e pela qual cada um, unindo-se a todos, não obedeça, portanto, senão a si mesmo, e permaneça tão livre como anteriormente. Tal é o problema fundamental cuja solução é dada pelo contrato social (ROUSSEAU, 1978, p.32).

O conceito rousseauniano que proporciona o elo entre interesses particulares e coletivos, liberdade e igualdade, indivíduo e coletividade não é outro senão a própria vontade geral. Sob a perspectiva de Rousseau, a vontade geral é a garantia de legitimidade das convenções políticas: a vontade política expressa pelo cabedal de leis constituídas pelos próprios cidadãos.

Neste ponto, defrontamo-nos com o paradoxo ao qual nos referimos partindo Do Contrato Social (1978) que reverbera na reflexão educacional contida no Emílio.

A obra $O$ Emílio ou Da Educação (1995), escrita em 1762 consiste em uma espécie de romance pedagógico que discorre acerca da educação de um órfão, Emilio, de seu nascimento até a idade de 20 anos.

A temática central do Emílío consiste na teorização da educação do homem através de seu retorno à natureza. A centralidade da ação educativa está no próprio educando e deve ocorre de modo natural, ou seja, em contato com a natureza, afastada 
da vida social e de forma a levar em consideração as necessidades espontâneas do processo de desenvolvimento da criança. O projeto educacional rousseauniano visa a naturalização do homem com vistas a reformar a sociedade (CAMBI, 1999).

O livro é dividido em 5 (cinco) partes que, respectivamente, correspondem a fases da vida e do processo educacional de Emílio. Livro I - fase da necessidade. Do nascimento aos dois anos. Livro II - fase da natureza. Dos dois aos doze anos. Livro III - fase da força. Dos doze aos quinze anos. Livro IV - Fase da razão e das paixões. Dos quinze aos 20 anos. Livro V - fase da sabedoria. Dos vinte aos vinte e cinco anos ${ }^{3}$.

Logo na primeira página do livro, Rousseau demarca: "tudo degenera nas mãos dos homens"; afirmação que justifica a necessidade da educação como mecanismo de conter a degradação que se estabelece quando da instituição da vida em sociedade. Pois que "um homem abandonado a si mesmo, desde o nascimento, entre os demais, seria o mais desfigurado de todos". Haja vista que "todas as instituições sociais em que nos achamos submersos abafaria nele a natureza e nada poria no lugar” (ROUSSEAU, 1995, p. 09). Abandonado à própria sorte, o homem seria como um arbusto esquecido á beira do caminho, que terminaria por ser morto pelos passantes.

Para Rousseau, "Tudo o que não temos ao nascer e de que precisamos adultos, énos dado pela educação" (ROUSSEAU, 1995, p. 10), mais precisamente, por três tipos de educação: a da natureza (o desenvolvimento interno de nossas faculdades e órgãos), a das coisas (nossa experiência em face dos objetos que nos afetam) e a dos homens (o uso que nos ensinam a fazer das outras formas de educação) (ROUSSEAU, 1995).

Em face do postulado de que o homem nasce bom, Rousseau propõe ser necessário que a educação parta dos instintos naturais da criança. Esta é a chamada educação negativa na qual o principal papel do educador seria o de preservar a natureza da criança, ao invés de formar prematuramente sua inteligência (educação positiva) ou "molestar de diversas maneiras" (ROUSSEAU, 1995) sua natureza com objetos que a circundam.

Na chamada educação positiva, segundo Rousseau, há sempre a marca de uma força pessoal que obriga, permite ou proíbe. Em contrapartida, o pequeno Emílio deve ser guiado à maneira do próprio mundo natural, ou seja, pelas leis do necessário, do possível e do impossível (MORAIS, 1986). Afirma o filósofo: "Deixai a natureza agir

\footnotetext{
${ }^{3}$ Esta abordagem, entretanto, concentra-se nos dois primeiros livros que tratam da educação do Emílio até a idade de 12 anos, que correspondem, respectivamente, às fases da necessidade e da natureza.
} 
durante muito tempo, antes de procurardes agir em lugar dela a fim de não contrariardes suas operações" (ROUSSEAU, 1995, p. 97).

$\mathrm{Na}$ educação positiva é o educador que faz a lei. Na educação negativa, ele apenas a revela. Assim, no propósito educacional de Rousseau, a liberdade seria uma espécie de lei e, portanto, segundo uma possível interpretação, coação. Mas, no ideário rousseauniano, uma coação não arbitrária (GROSRICHARD, 1980 apud MORAIS, 1986). Estabelece o filósofo: "A educação primeira deve portanto ser puramente negativa. Ela consiste não em ensinar a virtude ou a verdade, mas em preservar o coração do vício e o espírito do erro" (ROUSSEAU, 1995, p. 80).

Este aspecto aponta para questões sobremaneira relevantes acerca do pensamento de Rousseau: primeiramente, a constatação de que o projeto educacional do filósofo encontra-se intimamente relacionado à sua ideia de sociedade. Por conseguinte, a possível presença, em sua reflexão pedagógica, de um paradoxo semelhante ao encontrado no bojo de sua filosofia política, qual seja, a ideia de uma "naturalidade" forjada pela educação, de um "forçar" a ser natural e, portanto, livre.

No Emílio, perpassa amiúde a ideia de uma educação para a constituição de um determinado modelo de sociedade. Não é por acaso que as obras Do Contrato Social e Emílio ou Da Educação, por exemplo, foram publicadas quase concomitantemente no ano de 1762 (CERIZARA, 1990).

Segundo Freitas (2004), no pensamento de Rousseau, a educação e a política apresentam-se como áreas correlacionadas e, como tal, devem ser analisas. A publicação quase simultânea das supracitadas obras revelaria, assim, uma estratégia do próprio autor de induzir a uma aproximação entre ambas.

Rousseau compreende a educação como um processo balizado nos princípios da natureza como o modelo mais indicado para a formação do cidadão. Para Rousseau, a trajetória educacional dos homens tem início no seu nascimento e é empreendida, por primeiro, pela própria natureza. O desenvolvimento das faculdades humanas, começando na primeira infância, estende-se por toda a vida, propiciando-lhe um processo de aprimoramento de sua capacidade de atuar na vida em sociedade Desta feita, a educação, em Rousseau, seria um processo de formação de homens livres capazes de atuar significativamente na vida em sociedade (FREITAS, 2004).

Com efeito, para o filósofo, como exposto anteriormente, a vida social é um estado marcado pelo afastamento dos homens de sua natural condição de bondade e liberdade. Todavia, sendo a passagem ao estado de sociedade um fato inevitável, faz-se 
imprescindível que os homens aprendam a viver socialmente. Este papel não é senão da alçada da própria educação.

Assim, Rousseau, enfatiza a necessidade de uma educação que promova uma reaproximação do homem com a natureza, razão para, o autor "querer educar Emílio no campo, longe da canalha dos lacaios, os últimos dos homens depois de seus amos; longe dos maus costumes das cidades, o que o verniz com que se cobrem torna sedutores e contagiosos para as crianças" (ROUSSEAU, 1973, p. 82).

No Emílio, este processo ocorre ancorado ao mote de protegê-lo dos vícios e percalços da vida em sociedade. O Emílio deve ser minimamente afetado pelos elementos que degeneram e corrompem seu estado natural.

É neste sentido que na esfera educacional do pensamento de Rousseau, haveria um paradoxo semelhante ao encontrado no bojo de sua filosofia política, qual seja, a ideia de uma "naturalidade" forjada pela educação, de um "forçar" a ser natural e, portanto, livre.

Em Rousseau, o processo educacional configura-se em artifício humano com vistas ao resgate de uma naturalidade original. Tal processo fundamentar-se-ia pelo princípio da natureza, ou seja, à maneira do mundo natural.

A educação, em Rousseau, objetiva ou tem conexão com a vida em sociedade. $O$ Emílio é educado para ser um bom cidadão. Todavia, a preparação para a vida em sociedade tem como elemento fundamental sua proteção da corruptibilidade dessa mesma sociedade. Em Rousseau, uma educação que, em última instância, prepara o indivíduo para viver em sociedade, começa por sua proteção dos males sociais.

Contudo, não propomos que estes elementos apontem para lacunas no pensamento desse filósofo de envergadura inconteste. Assinalamos, tão somente, possíveis paradoxos (ou desdobramentos do paradoxo da liberdade) aos quais o próprio pensador genebrino afirma não fugir e que, ao contrário do que possam parecer inicialmente, corroboram a relevância de sua obra e a pertinência do estudo de suas ideias políticas e pedagógicas.

\section{Rousseau e o paradoxo da Educação}

Conforme Soëtard,

[...] O gênio de Rousseau que consagra a originalidade radical de sua empreitada, é o de ter pensado a educação como uma nova forma de um mundo engajado, contraditoriamente em um processo histórico de 
deslocamento. Enquanto seus contemporâneos mais ativos, também tocados pela "graça educacional", ocupam-se de "fabricar a educação"; e os mestres do pensamento se esforçavam, por meio da educação, de remodelar o homem, tornando-o senão um humanista, um bom cristão, um cavalheiro, um bom cidadão, Rousseau deixa de lado conjunto de técnicas, rompendo com todos os modelos e proclamando que a criança não tem que se tornar outra coisa senão naquilo que ela deva ser (SOËTARD, 2010, p. 13).

Com efeito, formulações de Rousseau acerca da educação podem ser depreendidas a partir da relação entre as obras Emílio ou Da Educação (2004) e Do Contrato Social (1983). Enquanto na primeira, Rousseau discute um projeto de educação natural do indivíduo; na última, o filósofo discorre sobre o modelo educacional e político com vistas ao desenvolvimento do cidadão.

O pensador contratualista propõe uma análise da concepção de infância e uma nova abordagem tangente ao processo de formação dos homens. Enquanto prática social, na concepção de educação apresentada por Rousseau, a formação humana é compreendida indissociavelmente das relações sociais.

Do Emílio, exara o desejo de conquista da própria liberdade e autonomia pessoal amalgamado ao conflituoso encontro com a realidade do mundo, do outro e da sociedade (SOËTARD, 2010, p. 17). Assim sendo, também na proposta educacional de Rousseau, encontramos uma relação paradoxal ou, ao menos um embate entre indivíduo e sociedade, interesses individuais e coletivos; à maneira do que ocorre em Do Contrato Social a propósito da ideia de forçar a ser livre.

O processo de preparação do Emílio para a vida em sociedade parte justamente da sua proteção desta mesma sociedade; ao menos nos dois primeiros livros que correspondem ao seu desenvolvimento até os doze anos. Haveria também na educação do Emílio um propósito de busca de uma original naturalidade por meio de um artifício humano, qual seja a educação.

Nesta sorte, a liberdade forçada do contrato social encontraria equivalência ou eco na esfera educacional: a naturalidade forjada; correlato ao paradoxo da liberdade, um paradoxo educacional (natural).

Nesta perspectiva, um dos elementos fundamentais da reflexão rousseauniana aponta precisamente para o estabelecimento de uma vontade geral que deveria respeitar a autonomia dos indivíduos sem, no entanto, vilipendiar as condições humanas originais dos homens. 
Assim, um processo educacional coerente em relação à noção de liberdade proposta por Marques (2010), na análise da obra de Rousseau, seria aquele que buscasse uma forma de ação que permitisse ao homem fazer-se livre, favorecendo, por intermédio de uma ação adequada aos fins perseguidos, à liberdade autônoma a despeito das relações sociais, ou melhor, no bojo da própria sociedade (SOËTARD, 2010).

Todavia, afigura-se necessário salientar, por fim, que o paradoxo, em Rousseau, não é sinônimo de contradição, lacuna ou incoerência. Trata-se, ao contrário de um argumento que transcende o senso comum ou mesmo o consenso. Ao contrário, a existência de paradoxos na obra de Rousseau confere a seu cabedal de ideias relevância ainda maior. Indubitavelmente, seus "textos são fundamentalmente críticos da organização social de seu tempo" e agudeza e a amplitude de seus argumentos "são tais que até hoje inspiram interpretações e controvérsias” (FONSECA JR, 2003, X).

\section{Referências}

ABBAGNANO. N. Dicionário de Filosofia. São Paulo: Martins Fontes, 1997.

ARISTÓTELES. Política. São Paulo: Nova Cultura, 1999 (Os Pensadores)

BOBBIO, N. (Orgs.). Dicionário de Política. $11^{\mathrm{a}}$ ed. Brasília: UNB, 1997. f. 272-275.

CAMBI, F. História da Pedagogia. São Paulo: Editora UNESP, 1999.

CASSIRER. E. The Question of Jean Jacques Rousseau. New York: Columbia University Press, 1954.

CERIZARA, B. A educação na infância. São Paulo: Scpione, 1990.

CHAPMAN, J. W. Rousseau - Totalitarian or Liberal?. New York: Columbia University Press, 1956.

COLETTI, L. From Rousseau to Lenin: studies in ideology and society. London: NLB, 1972.

COTTA, S. La position du problème de la politique chez Rousseau. In: COTTA, S. Études sur le contrat social de Jean-Jacques Rousseau. Paris: Societé des Belles Lettres, 1964.

CUNHA, A. G.. Dicionário Etimológico. Rio de Janeiro: Nova Fronteira, 1997. 
DOS SANTOS, L. R. Os paradoxos da liberdade no pensamento antropológico e político de Rousseau. Revista Linhas. Florianópolis, v. 18, n. 38, p. 304-343, set./dez. 2017.

FREITAS, L. B. A educação politica de Rousseau. Universidade Federal de Sergipe (Dissertação de Mestrado), São Cristóvão, 2004.

FONSECA JR, G. As múltiplas dimensões do pensamento de Rousseau. In: Rousseau e as Relações Internacionais. São Paulo: Imprensa Oficial do Estado, 2003.

GATTI JR, D. As ideias de Rousseau nos manuais de História da Educação com autores estrangeiros publicados no Brasil (1939-2010). Cadernos de História da Educação.v.13, n.2, p. 475-498. 2014.

HOBBES, T. Leviatã. Matéria, forma e poder de um Estado eclesiástico e civil. (Tradução de João Paulo Monteiro e Maria Beatriz Nizza da Silva). 3. ed. São Paulo: Abril Cultural, 1983. Col. Os Pensadores.

LOCKE, J. Segundo tratado Sobre o Governo. São Paulo: Abril Cultural, 1983.

Dois tratados sobre o governo. São Paulo: Martins Fontes, 1998.

MARQUES, J. O. A.. Forçar-nos a ser livres? O paradoxo da liberdade no Contrato Social de Jean-Jacques Rousseau. Cadernos de Ética e Filosofia Política. São Paulo: FFLCH-USP. n.16, p. 99-114. 2010.

MORAIS, E.M.M. Educação e Política: uma re-leitura de Rousseau. Faculdade de Educação: São Paulo, 12 (1/2), p. 199-215, jan/dez, 1986.

NASCIMENTO, M. M. Rousseau: da servidão à liberdade. In: WEFFORT, Franciso (Org). Os Clássicos da Política. São Paulo: Atica, 2006.

ROUSSEAU. JJ. Cartas escritas da montanha. Trad. Maria Constança Perez Pissarra e Maria das Graças de Souza. São Paulo: editora UNESP, 2006, p. 371-372.

. Discurso sobre a origem e os fundamentos da desigualdade entre os homens. São Paulo: Martins Fontes, 1999.

. Do Contrato Social. São Paulo: Abril Cultural, 1978.

. Du contrat social. OeuvresComplètes. V ol III, Paris: Gallimard, 1966.

. Emílio ou da educação.3 ed. São Paulo: Martins Fontes, 2004.

. Emílio ou da educação.3 ed. Tradução de Sergio Milliet, Rio de Janeiro: Bertrand Brasil, 1995.

SALINAS FORTES, L.R. Paradoxos do espetáculo. São Paulo: Discurso Editorial, 1997. 
SOËTARD, M. Jean-Jacques Rousseau. Tradução e organização: José Eustáquio Romão e Verone Lane Rodrigues Doliveira. Coleção Educadores. Recife: Fundação Joaquim Nabuco, EditoraMassangana, 2010. Disponível em: www.dominiopublico.gov.br/download/texto/me4675.pdf (Acesso 04 abr. 2017).

VEIGA, C. G. História da Educação. São Paulo: Ática, 2007.

WEFFORT, F C. (Org.). Os clássicos da política, v.1. 14ª ed. São Paulo: Ática. 2006.

Data de registro: $15 / 12 / 2018$

Data de aceite: 06/09/2019 